Published in final edited form as:

Anal Chem. 2020 January 07; 92(1): 647-653. doi:10.1021/acs.analchem.9b04502.

\title{
Fast Affinity Induced Reaction Sensor (FAIRS) Based on Fluorogenic Click Reaction for Quick Detection of Protein Biomarkers
}

\author{
Jingxin Liu ${ }^{1}$, Mohammed A. A. Abdullah ${ }^{1,2}$, Liwei Yang ${ }^{1}$, Jun Wang ${ }^{1, *}$ \\ ${ }^{1}$ Multiplex Biotechnology Laboratory, Department of Biomedical Engineering, State University of \\ New York at Stony Brook, Stony Brook, NY 11788 \\ ${ }^{2}$ Department of Chemistry, State University of New York, University at Albany, Albany, NY 12222
}

\begin{abstract}
Despite numerous biosensors currently available, the routine biomarker detection still largely relies on traditional ELISA and western blot. Those standard techniques are labor intensive and time consuming. Herein we introduce a fast affinity induced reaction sensor (FARIS) that overcomes a few limitations of traditional and emerging biosensors. FAIRS is a general, one-step method and is naturally specific in detection. FAIRS probes are composed of sandwich ELISA antibody pair that is conjugated with two fluorogenic click chemicals. This technology leverages significant differences of antibody affinity and chemical reaction rate, which are characterized to guide probe design. The stability, sensitivity, detection range and response time are fully characterized. Application to IL-6 detection using blood serum and cell culture medium demonostrates that FAIRS can quantify IL-6 with high sensitivity in one step. With the unique features, FAIRS probes may find broad applications in medical sciences and clinical diagnostics where quick detection of biomarkers is demanded.
\end{abstract}

\section{INTRODUCTION}

Simple, high-performance sensing technologies for the detection of protein biomarkers are critical for disease diagnosis. Conventional protein detection techniques largely rely on antibody-based, multi-step enzyme-linked immunosorbent assay (ELISA) and western blotting, which are usually time and labor consuming. In recent years, many emerging biosensors are introduced that feature the combination of high sensitivity and specificity, one step without washing, low-end instrument or device free, and fast response. Among them nanotechnology-based biosensors power the field to a new level. Surface plasmon resonance (SPR) in gold films with localized SPR and microring resonators has been developed to

\footnotetext{
*Corresponding Authors: jun.wang.5@ stonybrook.edu.

Supporting Information

The Supporting Information is available free of charge on the ACS Publications website at DOI: https://pubs.acs.org/doi/10.1021/ acs.analchem.9b04502.

Curve fitting for kinetics calculation; synthesis route of chemicals; NMR spectrum of chemical; influence of steric hindrance; FPLC and nanodrop result of conjugation.

The authors declare no competing financial interest.
} 
sense cytokine in real time. ${ }^{1-3}$ Plasmonic nanohole array further achieves label-free detection of biomarkers with large field of view for high-throughput assays. ${ }^{4-6}$

Nanoparticles and graphene have also been demonstrated for one-step detection of proteins when coupled with various mechanisms of surface enhanced Raman scattering, chemiluminescence, light scattering, and Förster resonance energy transfer (FRET). ${ }^{7-11}$ Many of those sensors need assistance of special instruments that a typical biomedical laboratory does not have, or they are only applicable in limited circumstances. A more general biosensor possessing multiple merits is highly demanded to fit the needs of clinical diagnosis, drug discovery, and biomarker screening.

Proximity response has been exploited to detect biomolecules simply in one step. For example, when DNAs are brought closely in space, thermodynamics of DNA hybridization can trigger binding or separation of DNA strands selectively. This property has been widely used to design DNA devices for molecular diagnostics, sensing and imaging applications. ${ }^{12-16}$ However, the sensor design generally involves a few DNAs and thus the unprocessed biological samples may interfere the assay accuracy. FRET occurs when fluorophores or quantum dots are in proximity due to affinity between biomolecules. ${ }^{17-19}$ But, the FRET based sensors usually have limited signal-to-noise ratio. The commercially available Alpha bead-based proximity immunoassay overcomes that limitation. It requires a special signal reading instrument that is not available in most research institutions. ${ }^{20}$ There are other proximity triggered biochemical reactions that have been applied in DNA detection. Split fluorescent proteins become fluoresce after re-assembly from two nonfluorescent fragments driven by additional DNA hybridization. The restoration of fluorescence takes only a few minutes when the tagged DNAs find their complementary parts. ${ }^{21,22}$ The similar idea for DNA detection is proximity fluorogenic click reaction. ${ }^{23,24}$ Click chemistry is fast, simple to use, stable in aqueous solution, and orthogonal to biochemical processes. ${ }^{25}$ It has shown remarkable value in molecular imaging, medicinal chemistry, drug development and discovery, and chemical biology. ${ }^{26-28}$ Fluorophore can be inactivated by click chemicals on the same molecule, and the fluorescence is restored after click reaction. ${ }^{24,29}$ Therefore, no washing step is required for sensing biomolecules.

Here we introduce a wash-free, fast-response biosensor that takes advantage of differential kinetics of antibody-antigen affinity and click reaction. Tetrazine (TZ)-BODIPY is covalently linked with capture antibody via long chain polyethylene glycol (PEG), and azabenzonorbornadiene (AN) is conjugated with detection antibody via the same PEG linker. This fast affinity induced reaction sensor (FAIRS) respond rapidly with $\mathrm{t}_{1 / 2}=6.5 \mathrm{~min}$, once IL- 6 as antigen is present in a solution. Without IL- 6 recombinant protein, the FAIRS probes can be stable for $>24 \mathrm{~h}$ without significant change of background or signal. Sensitivity and response time have been thoroughly studied. We have investigated the kinetics of the sensor and conclude the general design rule for proximity sensing. The FAIRS probes have been applied to detect IL-6 in human blood serum as well as in supernatants of stimulated microglial cells. Through quantification, we found the IL-6 concentrations detected by FAIRS probes are consistent with those by spiking and conventional ELISA. The combination of fast response, simple detection, high sensitivity and specificity, and high stability makes FAIRS superior to many proximity sensors, and 
thus FAIRS probes and the similar kind may find wide application in various fields when protein detection is concerned.

\section{EXPERIMENTAL SECTION}

\section{Chemicals and reagents}

tert-butyl 11-azatricyclo [6.2.1.02,7] undeca-2,4,6,9-tetraene-11-carboxylate (ChemScene), BODIPY-TZ-NHS ester (MW 613.24; WuXi AppTec), Biotin-PEG-SVA (MW 3400; Laysan Bio), $\mathrm{NH}_{2}$-PEG-COOH (MW 3400; Laysan Bio), Streptavidin (ProSpec), biotin (Sigma-Aldrich), 1-ethyl-3-(3-dimethylaminopropyl) carbodiimide (EDC; Pierce), Nhydroxysulfosuccinimide (Sulfo-NHS; Thermo Fisher Scientific), aliphatic amine latex beads ( $2 \%$ w/v, $0.4 \mu \mathrm{m}$; Thermo Fisher Scientific), Phosphate Buffered Saline Tablets (PBS; MP Biomedicals), 0.2M carbonate buffers (Alfa Aesar), ELISA MAX Standard Set Human IL-6 (BioLegend), TMB reagents (BioLegend), Amicon 100K cellulose centrifugal filter Unit (Thermo Fisher Scientific), Zeba 7K MWCO Spin Desalting Columns (Thermo Fisher Scientific), HyClone Iscove's Modified Dulbecco's Medium (IMDM; GE Healthcare BioSciences), Fetal Bovine Serum (FBS; GE Healthcare Bio-Sciences), trifluoroacetic acid (Sigma-Aldrich), Off-clot human Serum (ZenBio), and Dulbecco's Modified Eagle Medium/ Ham's F-12 (DMEM/F12; GE Healthcare Bio-Sciences), 1\% penicillin/streptomycin (Thermo Fisher Scientific), LPS (E. coli K12, $1 \mu \mathrm{g} / \mathrm{mL}$; Invitrogen).

\section{Cell culture and stimulation}

Human C20 microglial cell line is a gift from David Alvarez-Carbonell at Case Western Reserve University. C20 cells were cultured in DMEM/F-12 medium supplemented with $10 \% \mathrm{FBS}$ at $37{ }^{\circ} \mathrm{C}$ in humidified $5 \% \mathrm{CO}_{2}$ incubator. Before collection of supernatants, the cells were plated at a density of $2 \times 10^{5}$ cells/well on a 96-well plate. They were either stimulated by $1 \mu \mathrm{g} / \mathrm{ml}$ LPS for $24 \mathrm{~h}$ or kept in medium without stimulation as control. Culture medium from wells were collected and centrifuged at 3,000 rpm for $10 \mathrm{~min}$ to remove debris. The supernatants were obtained for measurement of IL- 6 concentration by various approaches.

\section{Preparation of $\mathrm{AN}-\mathrm{PEG}_{\mathbf{3 4 0 0}}$-detection antibody}

Tert-butyl 11-azatricyclo [6.2.1.02,7] undeca-2,4,6,9-tetraene-11-carboxylate (200mg) was deprotected first in Trifluoroacetic acid (TFA; $2 \mathrm{ml}$ ) to generate 7- azabenzonorbornadiene (AN). The reaction mixture was stirred for $1 \mathrm{~h}$ at $\mathrm{RT}$, and then the solvent was evaporated in vacuum. The crude product was purified by crystallization with ethyl acetate. To prepare AN-PEG 3400 -Biotin, the purified AN (50 mM in anhydrous DMF, $100 \mu \mathrm{L})$ was reacted directly with NHS-PEG 3400 -Biotin (10 mM in anhydrous DMF, $100 \mu \mathrm{L})$ for $1 \mathrm{~h}$ at room temperature, catalyzed by triethylamine $(0.25 \mu \mathrm{L})$. The product was filtered with $7 \mathrm{~K}$ Zeba spin column to remove excess AN.

$200 \mu \mathrm{L}$ of biotinylated detection antibody at $0.5 \mathrm{mg} / \mathrm{mL}$ was conjugated with $1 \mathrm{mg} / \mathrm{mL}$ streptavidin at the molar ratio of $1: 1$ for $0.5 \mathrm{~h}$. The excess streptavidin was removed by $100 \mathrm{~K}$ centrifugal filter (Amicon). Then $5 \mu \mathrm{L}$ of $\mathrm{AN}-\mathrm{PEG}_{3400}-\mathrm{Biotin}$ at $1 \mathrm{mM}$ was added to streptavidin-detection antibody conjugate, and the mixture was incubated for $1 \mathrm{~h}$ at room 
temperature. The excess AN-PEG 3400 -Biotin was removed by $2 \mu \mathrm{m}$ microbeads coated with streptavidin. The AN conjugated detection antibody was further purified and concentrated by $100 \mathrm{~K}$ centrifugal filter. To validate the final product, TZ $(17.7 \mu \mathrm{M}, 100 \mu \mathrm{L}$ in DMSO) were added in the final product $(1 \mathrm{mg} / \mathrm{mL}, 5 \mu \mathrm{L})$ and $100 \mu \mathrm{L}$ PBS on 96 -wells plates. The enhancement of fluorescence was used to determine whether the final conjugate was correctly produced. Fluorescence intensity was read by a microplate reader (Synergy H1 Hybrid Multi-Mode; BioTek) with excitation at $488 \mathrm{~nm}$ and emission at $525 \mathrm{~nm}$.

\section{Preparation of TZ-PEG $\mathbf{3 4 0 0}$-capture antibody}

Synthesis of fluorogenic BODIPY-TZ-NHS ester is assisted by WuXi AppTec (Figure S2 and S3). $300 \mu \mathrm{L}$ of this chemical at $16.3 \mathrm{mM}$ in anhydrous DMSO was mixed with $0.6 \mathrm{mg}$ $\mathrm{NH}_{2}-\mathrm{PEG}_{3400}-\mathrm{COOH}$ at molar ratio of 25 to 1 , and the mixture was stirred for $1 \mathrm{~h}$ at room temperature. The product was purified by $10 \mathrm{k}$ cellulose filter and washed 3 times with MES $(\mathrm{pH}=6)$ buffer. The solution was centrifuged at 10,000 rpm for three times to remove excess insoluble Tz-NHS ester, and adjust the concentration of TZ-PEG $3400-\mathrm{COOH}$ to $0.1 \mathrm{mM}$.

$2 \mathrm{mg}$ EDC and $5 \mathrm{mg}$ sulfo-NHS in MES buffer $(1 \mathrm{~mL}, \mathrm{pH}=6)$ were mixed and incubated for $15 \mathrm{~min}$, before taking $100 \mu \mathrm{L}$ of the mixture into $50 \mu \mathrm{L}$ TZ-PEG $3400^{-} \mathrm{COOH}$ at $0.1 \mathrm{mM}$. After $1 \mathrm{~h}$ incubation, 1.2 $\mu \mathrm{L}$ 2-mercaptoethanol was added to quench the unreacted EDC. The solution was desalted by $7 \mathrm{~K}$ zeba desalting column to remove small chemicals including byproducts and collect TZ-PEG 3400 -NHS.

IL- 6 capture antibody was concentrated to $1 \mathrm{mg} / \mathrm{mL}$ in $20 \mathrm{mM}$ carbonate buffer, measured by UV-Vis Spectrophotometer (Nanodrop ND-1000; Thermo Fisher Scientific). $100 \mu \mathrm{L}$ IL-6 antibody was mixed with $100 \mu \mathrm{L}$ freshly made TZ- $\mathrm{PEG}_{3400}-\mathrm{NHS}$ for $1 \mathrm{~h}$, before purification by Fast protein liquid chromatography (FPLC; BioRad) equipped with Superdex 200 10/300 GL column (GE Healthcare). The collected conjugate was further concentrated by $10 \mathrm{~K}$ centrifugal filter, and the concentration was measured by UV-Vis Spectrophotometer. To validate the final product, $100 \mu \mathrm{L}$ of $\mathrm{AN}$ at $10 \mu \mathrm{M}$ in PBS was added to $5 \mu \mathrm{L}$ of the conjugate. The fluorescence was monitored in real time, and >20 times increase of signal passed the validation.

\section{Calculation of reaction rate}

AN-PEG 3400 -detection antibody and TZ-PEG 3400 -capture antibody were mixed directly with IL-6 recombinant protein in PBS for determination of the reaction constant. The measurements were performed under pseudo $1^{\text {st }}$ order condition, using fixed amount of IL-6 protein $(8,000 \mathrm{pg} / \mathrm{mL})$ and an excess of antibody conjugates at $0.5,0.1,0.05$ and 0.01 $\mathrm{mg} / \mathrm{mL}$. Once the mixtures were loaded to wells of a 96 well plate, fluorescence signals were collected intermittently at select time points $(0,10,20,30,4050$, and $60 \mathrm{~min})$. Fluorescence intensity vs. time was fitted to a $1^{\text {st }}$ order exponential equation $\mathrm{y}=y_{0}+A_{1} \operatorname{Exp}\left(-\frac{x}{t}\right)$, where the pseudo $1^{\text {st }}$ order rate constant $\left(k_{o b s}\right)$ equals $1 /$ t. The obtained $k_{o b s}$ values were then plotted against antibody conjugate concentrations. The slope of fitted straight line corresponds to the $2^{\text {nd }}$ order rate constant $\left(k_{2}\right)$. Each measurement was repeated in triplicate. 


\section{One-step cytokine detection}

AN-PEG 3400 -detection antibody and TZ-PEG 3400 -capture antibody as FAIRS probes at final concentration of $0.05 \mathrm{mg} / \mathrm{mL}$ were mixed with human serum or cell supernatants in a 96 well plate. The fluorescence intensities were recorded in real time using a microplate reader. The fluorescence intensity of wells without sample or standard were used as blank. Off-clot human blood serum from healthy donors was purchased from ZenBio. Before measurement of IL-6 in human sample, standard IL-6 recombinant protein (Biolegend) was spiked into serum with final concentration at $100 \mu \mathrm{g} / \mathrm{mL}$. The serum was further diluted 2 times and 3 times for FAIRS detection and conventional ELISA assay.

For conventional ELISA assay, capture antibody at $10 \mu \mathrm{g} / \mathrm{mL}$ in PBS was incubated in a 96 well plate overnight at $4{ }^{\circ} \mathrm{C}$. After three washes with $3 \%$ BSA in PBS, various concentrations of IL- 6 recombinant proteins were added to wells and incubated for $2 \mathrm{~h}$. The unbound proteins were washed three times, and detection antibody with 100 times dilution was added to each well and incubated for $1 \mathrm{~h}$. The wells were washed for another three times, followed by incubation with diluted streptavidin-HRP conjugate with 500 times dilution for $30 \mathrm{~min}$. TMB reagents were transferred to wells to develop colors for reading of optical density with a microplate reader.

\section{Statistical analysis}

Fluorescence intensity data were analyzed using GraphPad Prism-6 (GraphPad Software). The same program was used to fit curves and find rate constants. Data points on plots were expressed as mean \pm S.D., with each repeated for at least three times experimentally. Significant differences between groups were determined using a one-way analysis of variance (ANOVA) with Dunnet's multiple comparisons test, considering P $<0.05$ as significant differences.

\section{RESULTS AND DISCUSSION}

$2^{\text {nd }}$ order kinetics of antibody-antigen affinity is normally above $1 \times 10^{6} \mathrm{M}^{-1} \mathrm{~S}^{-1},{ }^{30}$ while even the fastest TZ-trans-cyclooctene (TCO) click reaction can barely reach that rate. Such large discrepancy of reaction rates underlies the design of FAIRS probes for one-step detection. The sandwich ELISA antibody pair that is purchased from Biolegend and is validated by conventional well-plate based ELISA has been conjugated with their respective fluorogenic click chemicals to be FAIRS probes. When the probes are mixed together in a low concentration, click chemicals won't react significantly due to the relatively slow reaction rate. Once the antigen is present, the antibodies rapidly form a sandwich structure due to fast binding kinetics, which physically move click chemicals in proximity, leading to higher local concentration and click reaction to restore fluorescence.

Synthesis of FAIRS probes is shown in Figure 1. AN is conjugated with detection antibody through long chain $\mathrm{PEG}_{3400}$ mediated with streptavidin-biotin interaction. Possible steric hindrance has not been found to influence the binding affinity of detection antibody (Figure S4). Such a long arm is designed to ensure AN is approachable by TZ from capture antibody. TZ chemical contains BODIPY dye which fluorescence is suppressed by the 
unreacted TZ. AN as a strained dienophile reacts with TZ through irreversible inverseelectron-demand Diels-Alder reaction and release dinitriogen and release the product. ${ }^{23} \mathrm{TZ}$ and capture antibody are also spaced by the same $\mathrm{PEG}_{3400}$ to free $\mathrm{TZ}$ from spatial hindrance. The conjugation protocol has been optimized to have 3-5 $\mathrm{PEG}_{3400}$ spaced click chemicals on both capture antibody and detection antibody. Such ratio for capture antibody is controlled by the stochiometric chemical modification of antibody and is validated by FPLC spectrum (Figure S5), and the ratio for detection antibody is managed by the amount of streptavidin and biotinylated chemicals. In our previous studies, this ratio of modification with long chain oligonucleotide is the optimal one without significantly impairing antibody binding capability. ${ }^{31}$

The long chain $\mathrm{PEG}_{3400}$ is a hydrophilic, flexible polymer that facilitates solubility and exposure of AN and TZ in aqueous solutions or culture media. It is chemically inert and does not have nonspecific binding to most biomolecules. Once the $\mathrm{PEG}_{3400}$ is stretched, it can reach a length between $25 \mathrm{~nm}$ and $35 \mathrm{~nm}$, which is longer than a typical monoclonal antibody at 10-15 nm. ${ }^{32}$ Thus, even if AN and TZ are on the far ends of formed antibody sandwich structure, they still have a chance to physically contact and react to each other.

We have fully characterized the FAIRS probes in terms of turn-on fold, stability, response time and kinetics. Figure 2a shows 23-fold fluorescence turn-on signal when TZ-BODIPY is reacted with AN. The peak emission wavelength is measured to be $535 \mathrm{~nm}$. Excellent stability has been found for both reacted and unreacted FAIRS probes. The control sample without antigen IL- 6 marginally increases the signal by $5.1 \%$ over $24 \mathrm{~h}$, and the signal after detection of IL-6 keeps stable for the same period. When IL- 6 recombinant protein is added to the FAIRS probes, they immediately respond by increasing fluorescence signal within minutes (Figure $2 \mathrm{~b} \& 2 \mathrm{c}$ ). Various probe concentrations have been tested to characterize the response time and $2^{\text {nd }}$ reaction kinetics (Figure $\mathrm{S} 1$ ). All the curves completely reach plateaus after $\sim 20 \mathrm{~min}$. The fastest response was observed at $0.5 \mathrm{mg} / \mathrm{ml}(3.3 \mu \mathrm{M})$ concentration of probes; however, this condition is not recommended for practical application due to high cost of reagents. Despite different probe concentration used, the characteristic $t_{1 / 2}$ of half height is uniformly at about $6.5 \mathrm{~min}$ with standard deviation of $1.0 \mathrm{~min}$, which is comparable to other available one-step technologies for protein detection.

The $2^{\text {nd }}$ order rate constant of FAIRS detection is calculated to be $52,633 \mathrm{M}^{-1} \mathrm{~S}^{-1}$ (Figure 2d). It is lower than the rate constant of most antibody-antigen binding, possibly because the aforementioned $10^{6} \mathrm{M}^{-1} \mathrm{~S}^{-1}$ rate corresponds to single antibody-antigen binding instead of two antibody binding to the same antigen, and chemical modification of antibody may also influence the binding affinity to certain degree. We have also measured and obtained the $2^{\text {nd }}$ order rate constant of AN-TZ click reaction only at $51.5 \mathrm{M}^{-1} \mathrm{~S}^{-1} .24,33$ This indicates the proximity brought by antibody-antigen binding enhances AN-TZ reaction by $\sim 1,022$ times. Theoretically, the FAIRS probes at $0.05 \mathrm{mg} / \mathrm{ml}$ are equivalent to 200 molecules $/ \mu \mathrm{m}^{3}$. When in proximity, 3-5 molecules with average $25 \mathrm{~nm}$ separation distance result in between $1.9 \times 10^{5}$ to $3.2 \times 10^{5}$ molecules $/ \mu \mathrm{m}^{3}$, assuming all chemicals are accessible for the reaction. Or, the local concentration of AN or TZ has been theoretically boosted by 960 to 1600 times, which is not far away from the calculated 1,022 times increase of reaction rate. 
Therefore, significant increased local concentration is the main factor contributing to the fast response of FAIRS.

Figure 3 shows sensor response at various concentrations of recombinant IL-6 proteins. Except for $10 \mathrm{pg} / \mathrm{mL}$, all fluorescence intensities rise with time and reach plateau between $12.5 \mathrm{~min}$ and $20 \mathrm{~min}$. The fluorescence data at $30 \mathrm{~min}$ were used to generate calibration curve (Figure $3 \mathrm{~b}$ ), which shows linearity over $10^{2}$ dynamic range (the higher concentration was not measured due to significant deviation from the physiological condition). The limit of detection (LOD) is calculated to be $29 \mathrm{pg} / \mathrm{mL}$, higher than LOD by standard sandwich ELISA at $<10 \mathrm{pg} / \mathrm{ml}$. This tradeoff is saved by the fast response and simple procedure of our sensor. Better sensitivity could be achievable by other design of fluorogenic chemicals to improve signal-to-noise ratio and brightness.

The FAIRS probes have been applied to measure cytokine IL-6 in human blood samples that were spiked with $100 \mathrm{pg} / \mathrm{mL}$ IL-6 recombinant proteins. IL-6 is an important marker for diagnosis of inflammatory diseases such as sepsis where IL-6 level in blood can be elevated to a range of $\sim 150 \mathrm{pg} / \mathrm{mL}$ to $>1000 \mathrm{pg} / \mathrm{mL} .{ }^{34}$ Blood serum was diluted 2 times or 3 times to lower autofluorescence background before FAIRS detection. In both diluted serum samples, fluorescence signals are increasing over time, while they are significantly higher than background noise. After quantification using calibration curves, signal are converted to the diluted concentration, which is further multiplied by the dilution times to calculate the original concentration. The sample of $2 x$ dilution was calculated to contain $111.0 \mathrm{pg} / \mathrm{mL}$ IL- 6 before dilution, and the $3 \mathrm{x}$ dilution sample has $72.8 \mathrm{pg} / \mathrm{mL}$ IL- 6 before dilution. When the $3 \mathrm{x}$ dilution sample was analyzed, the real IL- 6 concentration was only $33.3 \mathrm{pg} / \mathrm{mL}$ close to detection limit. That may cause the significant deviation from the actual amount. Nevertheless, there is no statistical difference of IL- 6 concentration measured by these two dilutions.

The FAIRS probes have been applied to the medium supernatant of cultured cells without stimulation (control) and the supernatant after lipopolysaccharide (LPS) stimulation for 24 h. C20 cell line is derived from immortalized human primary microglia, and it maintains microglial morphology, surface markers, and immune responses of microglia. ${ }^{35,36}$ Upon stimulation, C20 cells produce an array of inflammatory factors including IL-1 $\beta$, IL-6, CCL2 and CXCL10. ${ }^{37}$ Our results in Figure 4c show IL-6 is detectable in the stimulated supernatant, while the control sample has negligible amount of IL-6. The quantified concentrations of IL- 6 by FAIRS method and by conventional well-plate based method were compared in Figure 4d. In both control samples and LPS stimulated samples, the quantified IL-6 is consistent between the two methods as they don't have significant differences statistically.

\section{CONCLUSION}

In summary, we have developed a differential kinetics driven FAIRS technique for rapid, one-step detection of antigens. The FAIRS detection is based on fast affinity of antibody and antigen and slow reaction of fluorogenic click chemistry. The sensor has been fully characterized, and the response time is found to be $6.5 \pm 1.0 \mathrm{~min}$. Our study discovered that 
the significant increase of local concentration of click chemicals due to tagged antibodyantigen binding quantitatively match the differences of the intrinsic $2^{\text {nd }}$ order rate constants. This provides a guideline for further design of such sensors taking advantage of kinetics discrepancy. The FAIRS probes have been applied to real samples and are found accurate in measuring IL-6 concentrations. With the multiple values including simple procedure of detection and high specificity and sensitivity, we envision that FAIRS can find broad applications in diagnosis of inflammatory diseases, drug and biomarker discovery, and those in a field setting.

\section{Supplementary Material}

Refer to Web version on PubMed Central for supplementary material.

\section{ACKNOWLEDGEMENT}

We would like to thank Dr. David Alvarez-Carbonell at Case Western Reserve University for providing C20 cell line, and Dr. Feng Li at Brock University for discussion. This research was supported by National Institute of Health (R01GM12898401) and NYSTEM (C32574GG) to J.W.

\section{REFERENCES:}

(1). Luchansky MS; Bailey RC J. Am. Chem. Soc 2011, 133, 20500-20506. [PubMed: 22040005]

(2). Milgram S; Cortes S; Villiers MB; Marche P; Buhot A; Livache T; Roupioz Y Biosens. Bioelectron 2011, 26, 2728-2732. [PubMed: 20961746]

(3). Wu SH; Lee KL; Chiou A; Cheng X; Wei PK Small 2013, 9, 3532-3540. [PubMed: 23606668]

(4). Li X; Soler M; Ozdemir CI; Belushkin A; Yesilkoy F; Altug H Lab chip 2017, 17, 2208-2217. [PubMed: 28585972]

(5). Li X; Soler M; Szydzik C; Khoshmanesh K; Schmidt J; Coukos G; Mitchell A; Altug H Small 2018, 14, e1800698. [PubMed: 29806234]

(6). Park J; Im H; Hong S; Castro CM; Weissleder R; Lee H ACS photonics 2018, 5, 487-494. [PubMed: 29805987]

(7). Huang X; Liu Y; Yung B; Xiong Y; Chen X ACS nano 2017, 11, 5238-5292. [PubMed: 28590117]

(8). Kokko T; Liljenback T; Peltola MT; Kokko L; Soukka T Anal Chem 2008, 80, 9763-9768. [PubMed: 19012418]

(9). Lee JS; Joung HA; Kim MG; Park CB ACS nano 2012, 6, 2978-2983. [PubMed: 22417160]

(10). Liu X; Dai Q; Austin L; Coutts J; Knowles G; Zou J; Chen H; Huo QJ Am. Chem. Soc 2008, 130, 2780-2782.

(11). Wu BY; Wang HF; Chen JT; Yan XP J. Am. Chem. Soc 2011, 133, 686-688. [PubMed: 21166409]

(12). Ge B; Huang YC; Sen D; Yu HZ Angew. Chem. Int. Ed. Engl 2010, 49, 9965-9967. [PubMed: 21104965]

(13). Li F; Lin Y; Le XC Anal. Chem 2013, 85, 10835-10841. [PubMed: 24138159]

(14). Seemann IT; Singh V; Azarkh M; Drescher M; Hartig JS J. Am. Chem. Soc 2011, 133, 47064709. [PubMed: 21401129]

(15). Tang Y; Lin Y; Yang X; Wang Z; Le XC; Li F Anal. Chem 2015, 87, 8063-8066. [PubMed: 26237634]

(16). Thomas JM; Chakraborty B; Sen D; Yu HZ J. Am. Chem. Soc 2012, 134, 13823-13833. [PubMed: 22835075]

(17). Chen MJ; Wu YS; Lin GF; Hou JY; Li M; Liu TC Anal. Chim. Acta 2012, 741, 100-105. [PubMed: 22840710] 
(18). Li H; Shi L; Sun DE; Li P; Liu Z Biosens. Bioelectron 2016, 86, 791-798. [PubMed: 27476061]

(19). Qiu X; Wegner KD; Wu Y-T; van Bergen en Henegouwen PMP; Jennings TL; Hildebrandt N Chem. Mater 2016, 28, 8256-8267.

(20). Yu ZT; Guan H; Cheung MK; McHugh WM; Cornell TT; Shanley TP; Kurabayashi K; Fu J Sci. Rep 2015, 5, 11339. [PubMed: 26074253]

(21). Demidov VV; Dokholyan NV; Witte-Hoffmann C; Chalasani P; Yiu HW; Ding F; Yu Y; Cantor CR; Broude NE Proc. Natl. Acad. Sci. U.S.A 2006, 103, 2052-2056. [PubMed: 16461889]

(22). Romei MG; Boxer SG Ann. Rev. Biophys 2019, 48, 19-44. [PubMed: 30786230]

(23). Wu H; Alexander SC; Jin S; Devaraj NK J. Am. Chem. Soc 2016, 138, 11429-11432. [PubMed: 27510580]

(24). Wu H; Devaraj NK Acc. Chem. Res 2018, 51, 1249-1259. [PubMed: 29638113]

(25). Hein CD; Liu XM; Wang D Pharm. Res 2008, 25, 2216-2230. [PubMed: 18509602]

(26). Jiang X; Hao X; Jing L; Wu G; Kang D; Liu X; Zhan P Expert Opin. Drug Discov 2019, 14 , 779-789. [PubMed: 31094231]

(27). Moses JE; Moorhouse AD Chem. Soc. Rev 2007, 36, 1249-1262. [PubMed: 17619685]

(28). Thirumurugan P; Matosiuk D; Jozwiak K Chem. Rev 2013, 113, 4905-4979. [PubMed: 23531040]

(29). Shieh P; Dien VT; Beahm BJ; Castellano JM; Wyss-Coray T; Bertozzi CR J. Am. Chem. Soc 2015, 137, 7145-7151. [PubMed: 25902190]

(30). Northrup SH; Erickson HP Proc. Natl. Acad. Sci. U. S. A 1992, 89, 3338-3342. [PubMed: 1565624]

(31). Ramirez LS; Wang JJ Visual. Exp 2016, e53644-e53645.

(32). Ikai A; Wang T Protein Stretching IV: Analysis of Force-Extension Curves, 2000; Vol. 39, p 3784-3788.

(33). Wu H; Cisneros BT; Cole CM; Devaraj NK J. Am. Chem. Soc 2014, 136, 17942-17945. [PubMed: 25495860]

(34). Harbarth S; Holeckova K; Froidevaux C; Pittet D; Ricou B; Grau GE; Vadas L; Pugin J Am. J. Respir. Crit. Care Med 2001, 164, 396-402. [PubMed: 11500339]

(35). Alvarez-Carbonell D; Garcia-Mesa Y; Milne S; Das B; Dobrowolski C; Rojas R; Karn J Retrovirology 2017, 14, 9. [PubMed: 28166799]

(36). Garcia-Mesa Y; Jay TR; Checkley MA; Luttge B; Dobrowolski C; Valadkhan S; Landreth GE; Karn J; Alvarez-Carbonell DJ Neurovirol. 2017, 23, 47-66.

(37). Davis RL, Buck DJ, McCracken K, Cox GW \& Das S. Neuroimmunol. Neuroinflammation 2018, $60,1-11$. 


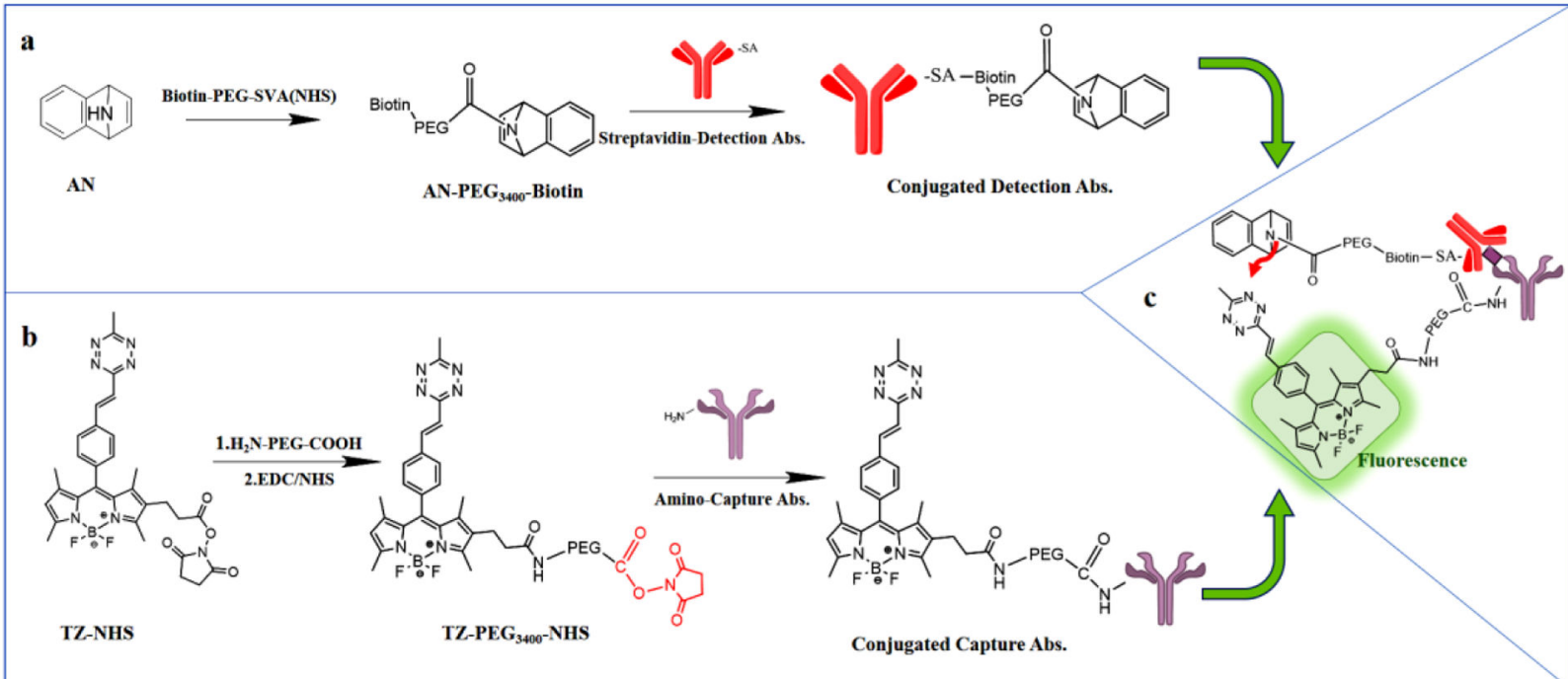

Figure 1.

Synthesis of FAIRS conjugates and fluorogenic click reaction. (a) Synthesis of AN conjugated detection antibody with $\mathrm{PEG}_{3400}$ spacer arm. (b) Synthesis of TZ conjugated capture antibody with $\mathrm{PEG}_{3400}$ spacer arm. (c) Schematic of fluorogenic click reaction with AN conjugated detection antibody and Tz conjugated capture antibody in the presence of antigen. 
a

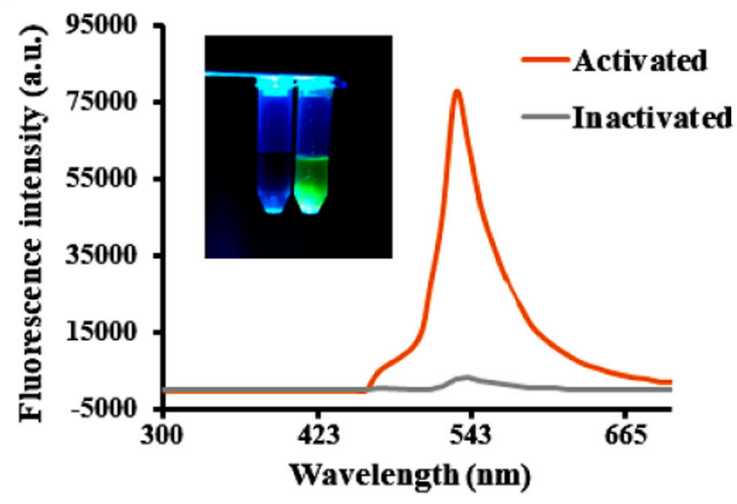

c

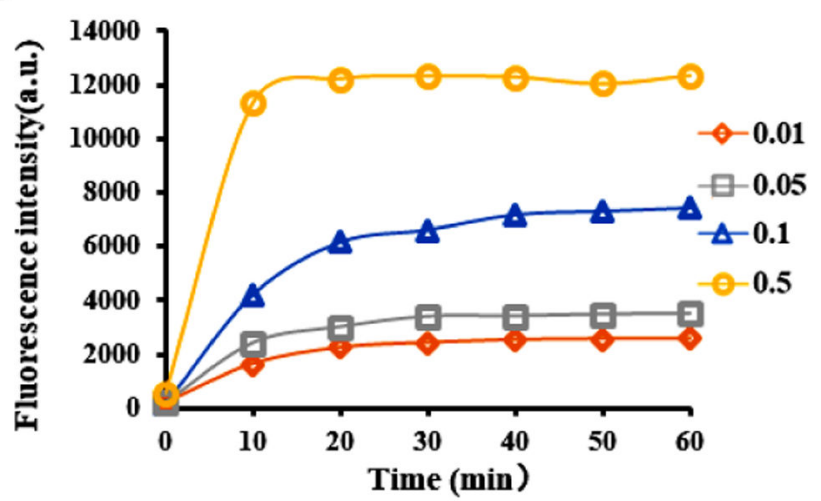

b

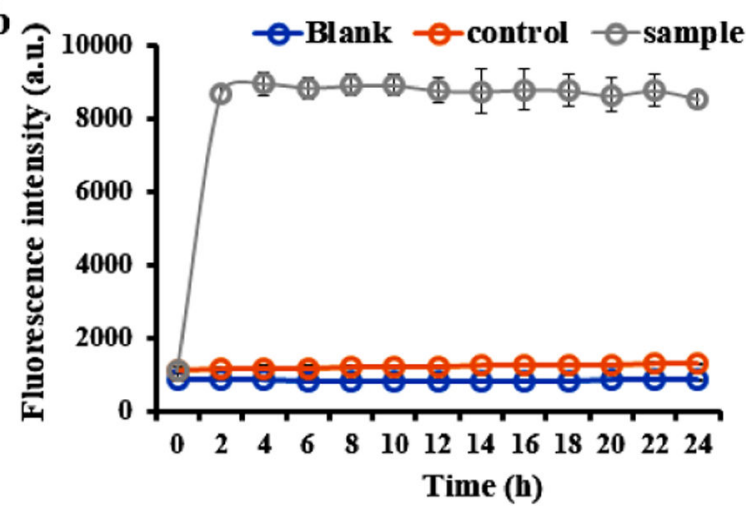

d

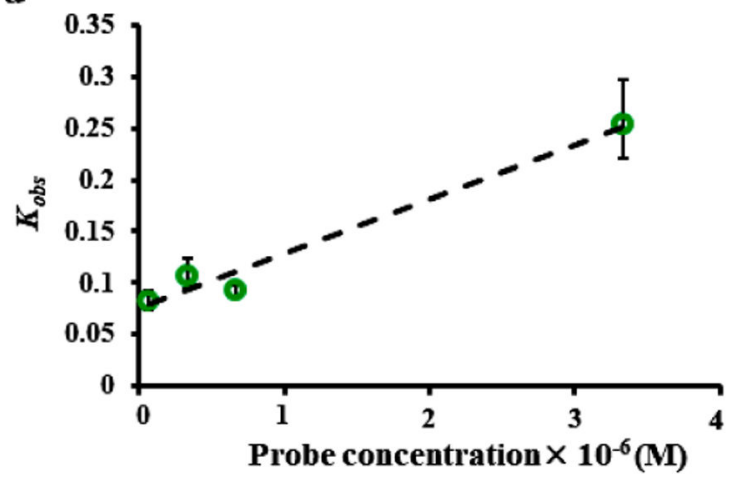

Figure 2.

(a) Fluorescence emission spectra of $\mathrm{TZ}$ in the inactivated state and TZ-AN. The inset picture shows both solutions under LED light at $480 \mathrm{~nm}$. (b) Stability of FAIRS detection signal for $24 \mathrm{~h}$. Sample: FAIRS detection of IL-6 protein at 8,000 pg/mL; Control: FAIRS detection without IL-6; Blank: background signal of PBS. (c) Real-time detection signal at various FAIRS probe concentrations from $0.01 \mathrm{mg} / \mathrm{mL}$ to $0.5 \mathrm{mg} / \mathrm{mL}$ with $8 \mathrm{ng} / \mathrm{ml} \mathrm{IL-6}$ antigen. (d) Linear regression of $k_{o b s} V s$. probe concentration. The vertical bars indicate the SDs $(n=3)$. 
a

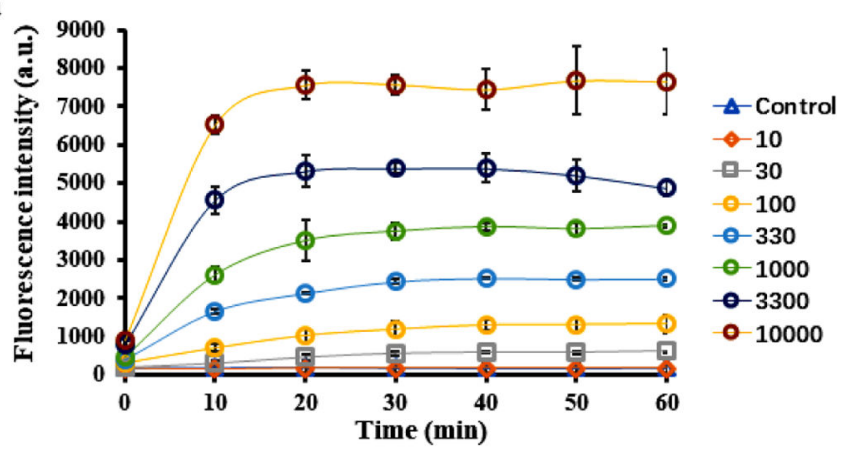

b

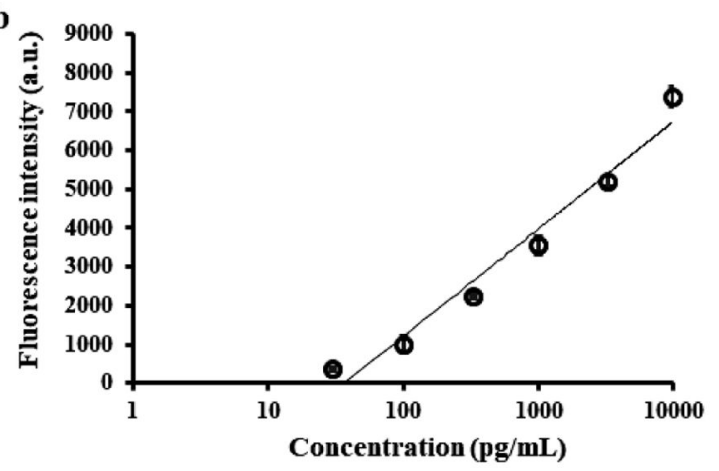

Figure 3.

(a) Real-time detection by FAIRS probes with IL-6 recombinant protein at various concentrations from $10 \mathrm{pg} / \mathrm{mL}$ to $10,000 \mathrm{pg} / \mathrm{mL}$. FAIRS probe concentration was fixed at $0.05 \mathrm{mg} / \mathrm{mL}$. The control curve shows the background signal from probes without IL-6 protein. The vertical bars indicate the SDs from three repeats. (b) Fluorescence intensities of FAIRS detection at various IL-6 protein concentration. Data at $30 \mathrm{~min}$ from (a) were generalized to produce this plot. 
$\mathbf{a}$

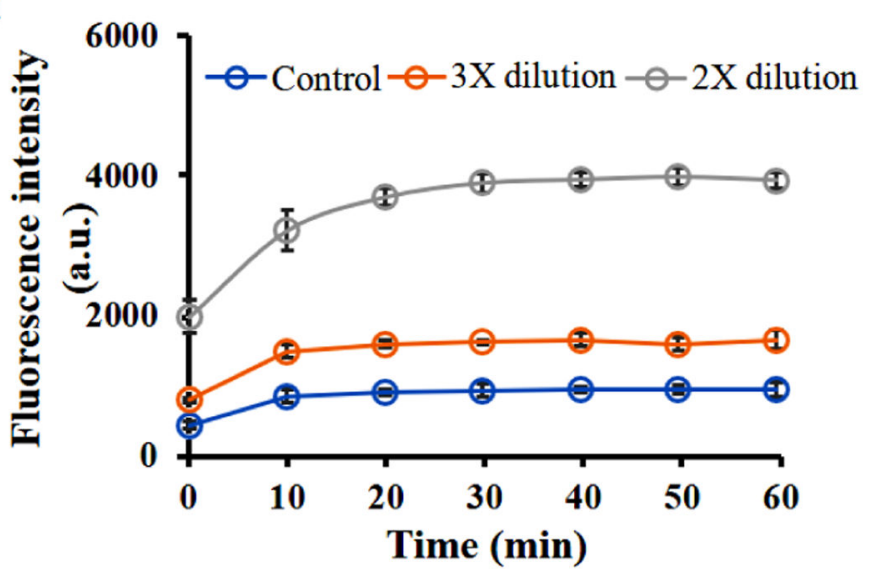

b

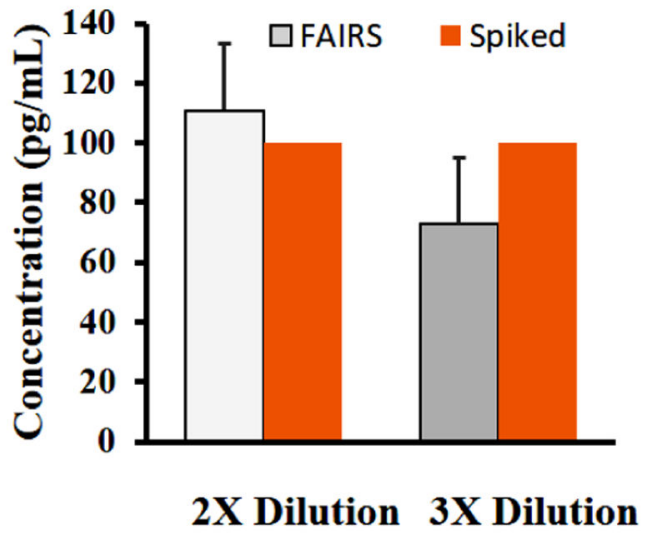

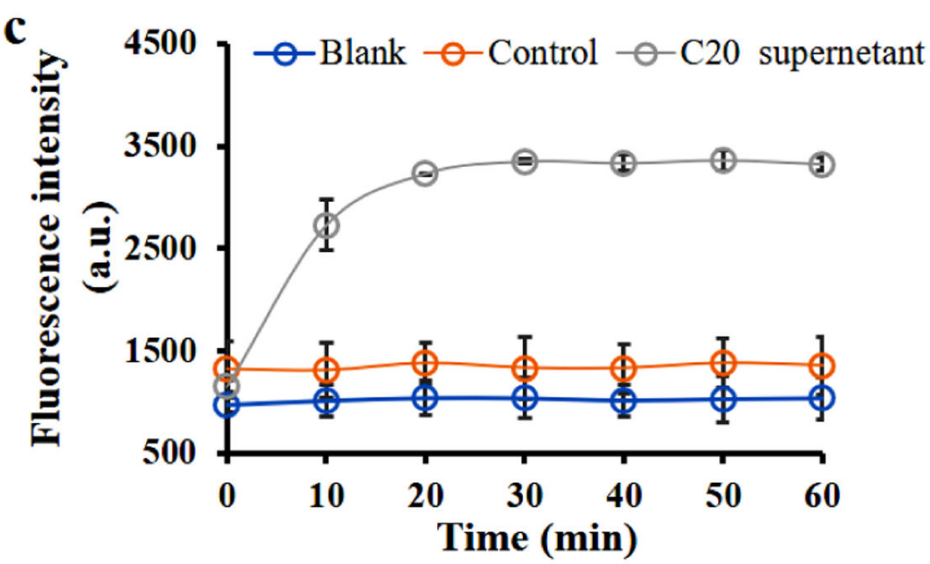

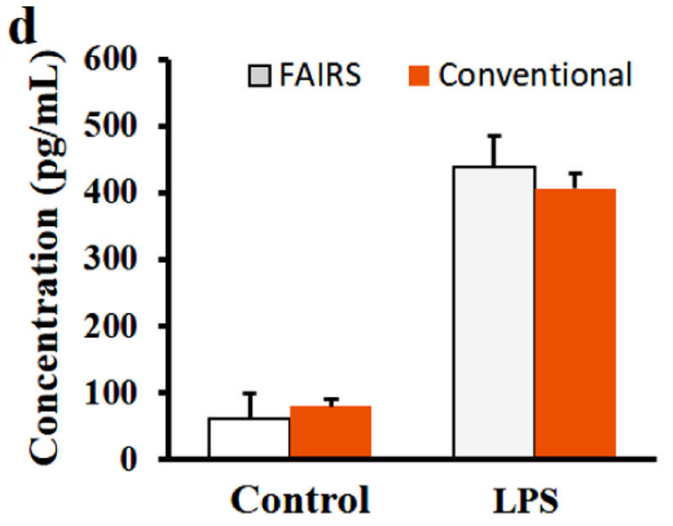

Figure 4.

One-step detection of IL-6 protein in spiked human serum and cell culture medium. (a) Real-time fluorescence intensities of FAIRS detection in diluted serum samples. Control: no spike of IL-6 protein in the serum sample. (b) Measured and calibrated IL-6 concentrations in $2 \mathrm{x}$ dilution sample and $3 \mathrm{x}$ dilution sample using calibration curve, and the comparison with spiked IL-6 amount in serum. (c) Real-time fluorescence intensities of FAIRS detection of IL-6 protein in C20 cell culture supernatants. C20 supernatant: LPS stimulated samples; Control: no stimulation; Blank: DMEM/F-12 medium only. (d) Comparison of measured IL-6 concentrations in stimulated cell supernatants by FAIRS method and by conventional ELISA method. Both measured data were converted to $\mathrm{pg} / \mathrm{mL}$ using calibration curves. Error bars correspond to SDs of three repeats. P values are $0.05(*)$ and $0.01(* *)$ with 0.05 considered statistically significant. 